\title{
PARTICIPATORY DESIGN DALAM KAJIAN PERANCANGAN STANDARDISASI MUSEUM SULTAN MAHMUD BADARUDDIN II
}

\author{
Sri Maharani Budi Haswati ${ }^{1}$, Erica Albertina ${ }^{2}$, Agrie Pratama Harwinanto ${ }^{3}$ \\ 1,2 Desain Komunikasi Visual, Fakultas Industri Kreatif, Telkom University, Jl. Terusan Buah Batu Bandung \\ 40257 \\ ${ }^{3}$ Desain Interior, Fakultas Industri Kreatif, Telkom University, Jl. Terusan Buah Batu Bandung 40257 \\ maharanibudi@telkomuniversity.ac.id, ericaalb@telkomuniversity.ac.id,agrie.harwinanto@gmail.com
}

\begin{abstract}
Abstrak: Dalam beberapa dekade terakhir, berbagai jenis museum di berbagai belahan dunia semakin gencar mengajak masyarakat untuk terlibat merayakan gairah berbudaya melalui berbagai jenis aktivitas. Mereka memperkenalkan mediamedia yang variatif dan berhasil mematahkan stereotip lama bahwa museum cenderung dikenal sebagai bangunan tempat penyimpanan koleksi dari warisan masa lampau semata. Sehingga muncul gagasan bahwa ditawarkannya pengalaman yang interaktif merupakan salah satu faktor utama yang mendorong orang-orang mau kembali mengunjungi museum. Apalagi, idealnya keberadaan museum dapat pula berkontribusi terhadap pemberdayaan komunitas masyarakat setempat. Namun faktanya, sebagian besar museum di luar Jawa masih jauh tertinggal di belakang dan masih terhalang oleh keterbatasan dana serta sumber daya manusia dalam upaya mengembangkan kualitasnya secara mandiri. Maka dari itu, penerapan Participatory Design menjadi sebuah alternatif di antara pendekatan desain konvensional lain yang dapat dimanfaatkan untuk menjembatani visi misi museum dengan kebutuhan masyarakat yang disasarnya. Penelitian ini merupakan tahapan awal dari perancangan desain yang menggunakan metode kombinasi (Observasi, wawancara, hingga analisis konten), dimaksudkan untuk mengidentifikasi kendala yang dihadapi oleh museum Sultan Mahmud Badaruddin II sehingga dapat menawarkan rancangan solusi yang tepat dari sudut pandang keilmuan desain. Sekaligus berfungsi merumuskan data siap olah yang dibutuhkan dalam tahapan perancangan desain selanjutnya agar mencapai standardisasi museum yang telah ditargetkan.
\end{abstract}

Kata kunci: Museum, Participatory Design, Desain, Komunitas 


\begin{abstract}
The global trend where museums attempt to actively engage with the public audience has been growing over the years. In the world cities, they embrace various media-from traditional to high technology and have successfully broken the old stereotype that museum was the conservative place to preserve the historical collections in particular. As a result, now it is commonly believed that offering interactive experiences is the primary reason for people to revisit the museum. In addition, a great museum is likely to affect how communities discover their passion for heritage through plenty of activities. Sadly, most of the museums that are located outside Java island, are still left behind. Most of these museums remain struggling with the classic issue, how to increase their quality with the least-possible budget and manage limited human resources. Hence, the Participatory Design method enables designers to assist the museum to overcome these obstacles. By utilizing mixedmethods research, this article aims to provide a creative guide based on the design and advertising study for Museum Sultan Mahmud Badaruddin II Palembang to achieve a standardized level according to their true potentials. At the same time, involving local communities in the process of designing a better museum for everyone.
\end{abstract}

Keywords: Museum, Participatory, Design, Community

\title{
PENDAHULUAN
}

Berdasarkan Surat Keputusan Menteri Kebudayaan dan Pariwisata (2009) pada Bab 1 Ketentuan Umum, Pasal 1 No.1, museum merupakan lembaga penyimpanan, perawatan, pengamanan, dan pemanfaatan bendabenda materiil hasil budaya manusia serta alam dan lingkungannya guna menunjang upaya perlindungan dan pelestarian kekayaan budaya bangsa. Sementara itu, pada Edaran Peraturan Pemerintah Republik Indonesia No.66 (2015) tentang museum, menyatakan bahwa museum melindungi, mengembangkan, memanfaatkan koleksi, dan mengkomunikasikannya kepada masyarakat. Dari kedua definisi tersebut, maka dapat disimpulkan bahwa fungsi dasar dari museum telah bertransformasi tidak hanya menjadi semacam gudang penyimpanan koleksi historis semata-namun sepatutnya ikut berperan sebagai pusat pendidikan, penelitian, hingga pariwisata. Maka dari itu, dibutuhkan berbagai langkah tata kelola permuseuman yang 
memenuhi standar, baik nasional maupun internasional. Seperti yang dicantumkan pada tabel 1 mengenai tiga jenis indikator Standardisasi Museum (Anonim, N.D) berdasarkan aspek Humas dan Pemasaran.

Tabel 1 Contoh Standardisasi Museum jika ditinjau dari aspek Humas \& Pemasaran

\begin{tabular}{lll}
\hline \multicolumn{2}{c}{ Poin V - Pendanaan: } & Aktivitas Hubungan Masyarakat dan Pemasaran \\
Museum Tipe A & Museum Tipe B & Museum Tipe C \\
\hline $\begin{array}{l}\text { Kebijakan dan Prosedur } \\
\text { Operasional Standar } \\
\text { hubungan masyarakat dan } \\
\text { pemasaran }\end{array}$ & $\begin{array}{l}\text { Kebijakan hubungan } \\
\text { masyarakat dan pemasaran }\end{array}$ & $\begin{array}{l}\text { Aktivitas hubungan } \\
\text { masyarakat dan } \\
\text { pemasaran }\end{array}$ \\
\hline $\begin{array}{l}\text { Kegiatan promosi yang } \\
\text { dilakukan museum }\end{array}$ & Dokumen promosi kegiatan & Sarana informasi dalam \\
& $\begin{array}{l}\text { yang dilakukan museum } \\
\text { secara lisan, tertulis, gambar }\end{array}$ & $\begin{array}{l}\text { bentuk media cetak dalam } \\
\text { baha Indonesia. }\end{array}$ \\
& (visual), dan/atau & \\
\hline $\begin{array}{l}\text { Media untuk menyalurkan } \\
\text { opini publik kepada }\end{array}$ & Sarana informasi dalam & \\
museum & bentuk media cetak & \\
& dan/atau media elektronik & \\
dalam bahasa Indonesia & \\
Inggris & dan/atau Inggris & \\
barana informasi dalam & & \\
\hline
\end{tabular}

sumber: (Direktorat Pelestarian Cagar Budaya dan Permuseuman et al., 2017)

Di Indonesia sendiri terdapat 435 jumlah museum yang resmi terdaftar di Pusat Data dan Statistik Dikbud (2019), ratusan di antaranya masih banyak didominasi oleh provinsi-provinsi yang tersebar di pulau Jawa. Dapat dilihat pada Tabel 2, daerah Sumatera, khususnya Sumatera Selatan, secara kuantitas hanya tercatat sekitar 7 museum yang diakui oleh Pemerintah. Dengan satu museum sudah berstatus tipe A, yakni Museum Provinsi Balaputradewa -6 (enam) museum sisanya masih tergolong dalam tipe $C$ 
(Direktorat Pelestarian Cagar Budaya dan Permuseuman et al., 2017). Padahal sebagaimana yang diketahui bahwa Palembang memiliki potensi wisata sejarah yang sangat besar, mengingat secara historis ada banyak sekali kekayaan hasil budaya sejak masa-masa menguatnya pengaruh kerajaan Sriwijaya sebagai salah satu bandar perdagangan yang menguasai Sumatra, Semenanjung Melayu (Yeo, 2013), termasuk Malaka hingga Siam di Thailand. Berlanjut dengan dengan lahirnya produk-produk akulturasi dari intensnya aktifitas para pendeta Budha, pedagang Tiongkok, serta India yang mengiringi bangkitnya era kesultanan setelah runtuhnya raksasa maritim tersebut. Namun bagaimanapun, warisan kebudayaan masyarakat Sumatera Selatan yang belum bisa dikelola secara maksimal tidak dapat memberikan manfaat yang signifikan terhadap tumbuhnya ekosistem wisata historis, bahkan sulit untuk merambah ke industri kreatif sekalipun. Hal ini jelas mengindikasikan adanya kendala besar yang dihadapi oleh pengelola Museum Sultan Mahmud Badaruddin II sehingga memerlukan partisipasi aktif dari berbagai pihak untuk mencapai standardisasi museum Tipe A.

Museum Sultan Mahmud Badaruddin II yang dikelola oleh Pemerintah Kota Palembang menjadi salah satu objek studi kasus menarik yang sementara digarap oleh penelitian ini sebagai titik tolak perancangan desain dan promosi museum ke depannya. Terletak di Jalan Ratu Sianum Lr. R. H. Umar No. 663, 1 llir Palembang-sehingga persis bersisian dengan sungai Musi dan berpapasan dengan jembatan Ampera yang dikenal cukup ikonik, Museum Sultan Mahmud Badaruddin II merupakan satu-satunya bangunan museum di Bumi Sriwijaya yang masuk dalam kategori cagar budaya. Akan tetapi menempati lokasi strategis tidak serta merta membuat museum yang mulai resmi beroperasi sejak tahun 2006 itu dapat dengan mudah bertransformasi sebagai destinasi wisata favorit masyarakat Palembang maupun para pelancong yang berasal dari luar Sumatera Selatan. 
Tabel 2 Jumlah Warisan Cagar Budaya \& Museum yang tersebar di setiap Provinsi di Indonesia tahun 2018 menurut Laporan Statistik Kebudayaan

\begin{tabular}{rlrr}
\hline No. & Provinsi & $\begin{array}{r}\text { Cagar Budaya } \\
\text { Cultural Heritage }\end{array}$ & $\begin{array}{r}\text { Museum } \\
\text { Museum }\end{array}$ \\
\hline 1 & DKI Jakarta & 150 & 64 \\
2 & Jawa Barat & 129 & 36 \\
3 & Banten & 28 & 5 \\
4 & Jawa Tengah & 397 & 54 \\
5 & DI Yogyakarta & 535 & 44 \\
6 & Jawa Timur & 158 & 45 \\
& & & 9 \\
7 & Aceh & 33 & 18 \\
8 & Sumatera Utara & 33 & 18 \\
9 & Sumatera Barat & 181 & 9 \\
10 & Riau & 25 & 3 \\
11 & Kepulauan Riau & 173 & 5 \\
12 & Jambi & 20 & 7 \\
13 & Sumatera Selatan & 9 & 3 \\
14 & Bangka Belitung & 21 & 2 \\
15 & Bengkulu & 58 & 2 \\
16 & Lampung & 7 & \\
& & & 5
\end{tabular}

sumber : (Hadi et al., 2019)

Dari keterangan yang diperoleh, kurang lebih diperkirakan ada 60 (enam puluh) pengunjung yang datang ke museum setiap hari-di mana mayoritas dari pengunjung merupakan sekelompok murid sekolah yang sedang mengikuti study tour atau rombongan peneliti dari luar kota. Akan tetapi, kualitas dari puluhan kunjungan ke Museum SMB II dalam sehari dirasa masih sangat jauh dari apa yang diharapkan oleh semua pihak, sebagaimana yang diakui oleh pengelola museum maupun dari sisi para pengunjung itu sendiri. Dengan jumlah koleksi yang diperkirakan hanya berjumlah 700 (tujuh ratus) buah, ditambah keterbatasan sumber daya manusia dan minimnya ketersediaan media-media penunjang komunikasi yang interaktif, menghasilkan hipotesis bahwa target museum dalam mengedukasi pengunjung belum dapat terpenuhi. Terkait dengan pembahasan mengenai 
indikasi maupun parameter keberhasilan museum tersebut akan dijawab pada riset-riset mendatang sebagai bagian dari penelitian yang berkelanjutan ini.

\section{METODE PENELITIAN}

Beberapa jenis metode penelitian yang digunakan untuk mengumpulkan data primer sehingga dapat mengembangkan sebuah rancangan dasar pengembangan koleksi bagi Museum Sultan Badaruddin II antara lain: Observasi Partisipan, Wawancara Terbuka, FGD (Forum Group Discussion) bersama para pengelola berbagai museum di Palembang, dan kuesioner terstruktur dengan mengikuti prinsip dasar dari Participatory Design. Alasan dipilihnya Participatory Design untuk mengembangkan Museum SMB II dalam mencapai standardisasi museum Tipe A dibandingkan dengan strategi desain konvensional lain seperti pitching desain, sayembara, maupun jasa konsultasi desain-terdapat pada faktor partisipasi dan interaksinya. Tidak hanya berorientasi pada user atau pengguna akhir, metode ini juga dapat melibatkan para partisipan dari latar belakang, pengalaman, ketertarikan, dan profesi yang bervariasi sehingga meningkatkan kualitas data sejak penelitian hingga ke tahap perancangan desain (Sanders, 2010).

Dengan demikian, pada tanggal 9 Maret 2020, melalui Observasi Partisipan, terdapat kesempatan untuk bergabung sebagai anggota dari rombongan pengunjung museum agar dapat mengamati pengalaman personal selama mengikuti tur singkat bersama edukator museum. Di waktu yang bersamaan, peneliti mengoleksi beberapa foto dari Museum Sultan Badaruddin II sekaligus merangkum hasil wawancara terbuka bersama beberapa pengurus museum. Sekaligus dibagikanlah beberapa lembar format 
kuesioner yang harus diisi oleh Kepala Seksi Permuseuman dan Bangunan sehingga berbagai jenis data yang berhasil dikoleksi dapat saling melengkapi satu sama lain sekaligus memperkaya insight penelitian, utamanya dalam proses kajian dan analisis data kualitatif.

Mengingat kendala yang sementara dihadapi oleh pihak Museum Sultan Mahmud Badaruddin II tergolong cukup kompleks-dimana masalah terbesar museum saat ini bukan hanya dari ketersediaan koleksi, namun juga menyangkut konservasi struktur dan peningkatan kualitas sumber daya manusianya-maka dilakukanlah pembatasan topik melalui metode klasifikasi data sederhana berdasarkan ruang lingkup dari masing-masing kendala yang berhubungan dengan penerapan ilmu Desain dan Advertising. Klasifikasi data sangat berguna agar konsep pemecahan masalah dapat dialamatkan kepada tenaga profesional sesuai dengan kebutuhan serta target dari museum itu sendiri. Berdasarkan data yang berhasil dikumpulkan pada metode-metode sebelumnya, maka klasifikasi data terkait ilmu Desain dan Advertising dibagi menjadi tiga topik utama, yakni Branding \& Promotion, Business Plan, dan Community Development.

\section{HASIL DAN DISKUSI}

Berlokasi di salah satu kawasan destinasi pariwisata utama kota Palembang, yaitu tepian sungai Musi dan jembatan Ampera, jumlah pengunjung museum ini terbilang relatif rendah, yaitu 60 (enam puluh) pengunjung per hari. Melihat potensi tarikan wisatawan pada kawasan ini, maka dilakukan survei terhadap site dan kondisi bangunan Museum SMB II sebagai tahapan awal penelitian, untuk mengetahui faktor-faktor apa saja yang menjadi penghambat bagi museum ini dalam menarik pengunjung. 
Sebagaimana teori Cooper (1993) dalam Suwena dan Widyatmaja (2010) mengenai empat komponen utama pariwisata, yaitu attraction, accessibility, amenity dan ancillary, maka faktor-faktor yang diobservasi difokuskan pada atribut aksesibilitas yang memiliki keterkaitan erat dengan sarana prasarana untuk mengarahkan pergerakan pengunjung untuk mencapai museum SMB II. Penilaian terhadap atribut aksesibilitas yang menjadi variabel dalam survey awal ini dilakukan dengan melakukan observasi terhadap tiga sub-variabel yaitu ketersediaan transportasi umum, akses, dan rambu petunjuk atau sign system.

Lokasi museum SMB II yang berada dalam kawasan destinasi unggulan kota Palembang, yaitu jembatan Ampera, tepian sungai Musi dan benteng Kuto Besak, relatif mudah untuk dijangkau dengan transportasi publik. Terdapat beberapa alternatif transportasi umum yang memiliki pemberhentian di sekitar Museum SMB II, yaitu LRT (stasiun LRT Ampera), Angkot (Ampera), dan Bus Trans Musi (Halte Monpera), dimana jarak pemberhentian ketiga moda transportasi ini hanya berkisar 500 meter dari museum.

Indikator berikutnya ialah akses. Dalam kaitannya terhadap perihal wayfinding, akses dapat diklasifikasikan menjadi dua jenis yaitu akses sebagai sarana jalan (pedestarian, setapak, jalan raya), dan akses sebagai sarana visual dalam melakukan navigasi. Tersedianya akses visual menuju atribut-atribut yang mempunyai informasi merupakan faktor yang sangat berpengaruh terhadap kemudahan dalam melakukan navigasi (Arthur and Passini, 1992).

Dalam pengamatan yang dilakukan, jalan masuk kawasan museum SMB II berada di jalan Merdeka, dimana jalur ini memiliki lebar jalan yang dapat dilalui bus berukuran sedang. Namun, lokasi jalur masuk yang tidak berhadapan langsung dengan museum SMB II, berpotensi untuk menyulitkan 
pengunjung untuk menemukan akses jalan ini. Kawasan parkir kendaraan museum SMB II berada dalam area parkir terpadu, di mana beberapa bagian dari parkiran tersebut digunakan dengan berbagi bersama pengunjung dari Benteng Kuto Besak, dermaga BKB, dan destinasi lainnya yang berada disana.

Lebih lanjut, lokasi yang dikelilingi oleh destinasi pariwisata lainnya menyebabkan museum ini juga harus bersaing dengan destinasi-destinasi lain yang memiliki massa bangunan yang lebih masif. Berada di tengah-tengah destinasi unggulan tersebut, eksisting bangunan Museum SMB II secara visual kurang dapat bersaing dan terhalang oleh destinasi lainnya, sehingga menyebabkan akses visual menuju museum dari jalan raya ataupun titik pemberhentian angkutan umum menjadi tidak maksimal.

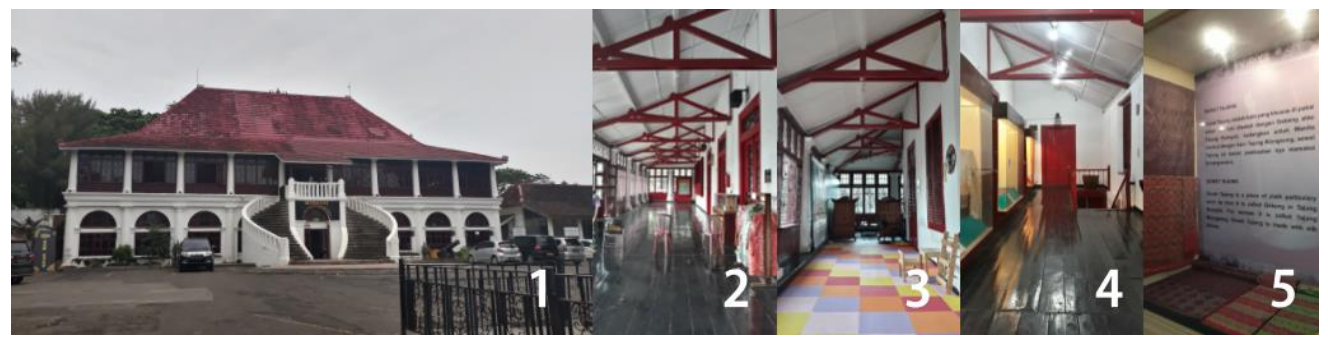

Gambar 1 Kondisi fisik Bangunan, ruangan, dan beberapa koleksi Museum Sultan Mahmud Badaruddin II: Urutan nomor 1) Tampilan Depan Bangunan; 2) Koridor Utama Lantai 2 Museum; 3) Area Anak-anak; 4) Koleksi tentang Circle of Life di ruangan bagian belakang lantai 2 Museum; 5) Area Koleksi Kain Songket di lantai dasar yang tidak dibuka untuk umum; Sumber: Haswati, 2020

Faktor berikutnya ialah keberadaan penanda informasi atau lokasi yang biasa dikenal dengan Sign System, yang belum memadai. Penanda lokasi yang biasanya menjadi substitusi dari akses visual langsung yang terbatas belum memenuhi fungsinya secara maksimal, sehingga pergerakan massa yang berada di sekitar area museum tidak terarahkan ke lokasi Museum SMB II. Bahkan ketika halaman depan museum sudah cukup luas untuk menampung volume kendaraan pengunjung dalam jumlah besar, adanya 
sebuah kolam air mancur yang tidak terawat justru memperburuk kejelasan visual terhadap bangunan museum. Ditambah lagi di sekitar zona parkir terdapat pula dua patung arca besar yang tidak terurus meskipun telah diatapi serta dipagari dengan baik.

Beberapa contohnya masalah yang ditemui antara lain: ketiadaan Sign System yang dapat membantu pengunjung untuk memahami arah maupun alur museum. Trulove et al. (2000) menggambarkan peran Sign System dalam menjawab pertanyaan-pertanyaan naluriah manusia dalam mengatasi problematika spasial-yakni sebagai petunjuk bagaimana cara mencapai suatu arah, khususnya navigasi untuk kembali saat si pengguna kehilangan jejak. Tidak hanya itu, seperangkat sistem penanda yang efektif dapat menciptakan sense of order sebagai perwujudan pengalaman emosional melalui transisi ruang demi ruang dalam sebuah bangunan.

Selain itu, label deskripsi mengenai interpretasi satu benda koleksi (kalaupun ada) berupa paragraf teks yang dicetak tanpa menghiraukan sama sekali prinsip-prinsip dasar komunikasi visual, seperti tingkat keterbacaan, gaya penulisan, hingga media cetaknya. Padahal tentu saja setiap benda yang terpajang di museum tidak mampu untuk mengkomunikasikan dirinya sendiri sehingga dibutuhkan bantuan para interpreter yang memahami kebutuhan tersebut: kurator, edukator, dan desainer untuk 'menghidupkan' kembali koleksi tersebut melalui visualisasi atau penjabaran cerita yang menarik sehingga dapat dipahami dan diapresiasi oleh setiap pengunjung, bahkan yang awalnya sama sekali tidak memiliki pengetahuan tentang koleksi yang bersangkutan (Boylan, 2004). 


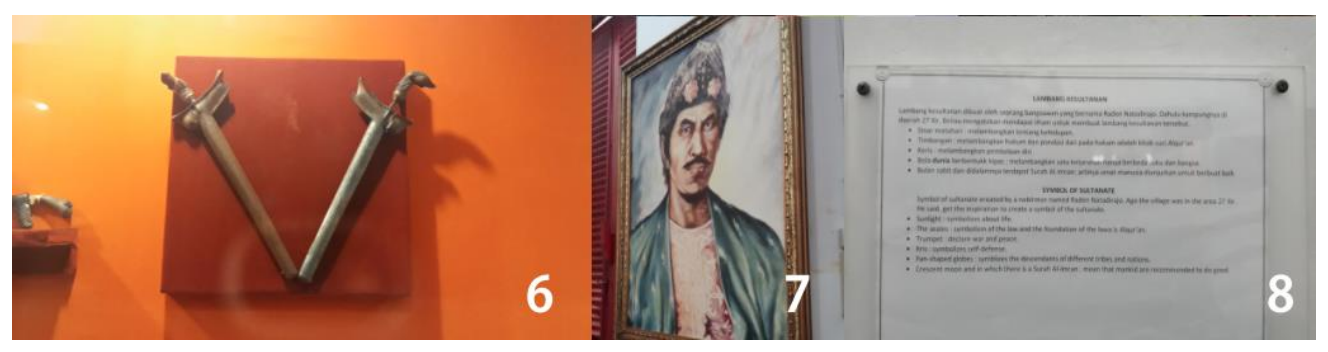

Gambar 2 Koleksi Museum 6) Beberapa keris Jawa terpajang tanpa satupun potongan informasi; 7) Lukisan Sultan Mahmud Badaruddin II yang dipajang seadanya; 8) Contoh keterangan dibawah koleksi; Sumber: Haswati, 2020

Di lain sisi, dengan penerapan ilmu Desain dan strategi Periklanan secara konsisten diyakini dapat menunjang proses standardisasi museum sesuai dengan pedoman kebijakan yang telah dirumuskan oleh 3 (tiga) Direktorat Pendidikan, Kebudayaan, dan Cagar Budaya (2017) pada poin 13yakni poin hubungan masyarakat dan pemasaran mengenai "aktivitas yang berkenaan dengan pendokumentasian, promosi, dan pencitraan museum kepada publik". IImu desain secara praktis memungkinkan museum untuk melakukan proses pengarsipan serta manajemen data kreatif melalui aktivitas riset (mengumpulkan kembali, memetakan, dan mengolah) secara efisien agar dapat dikembangkan menjadi materi desain/aset visual siap pakai.

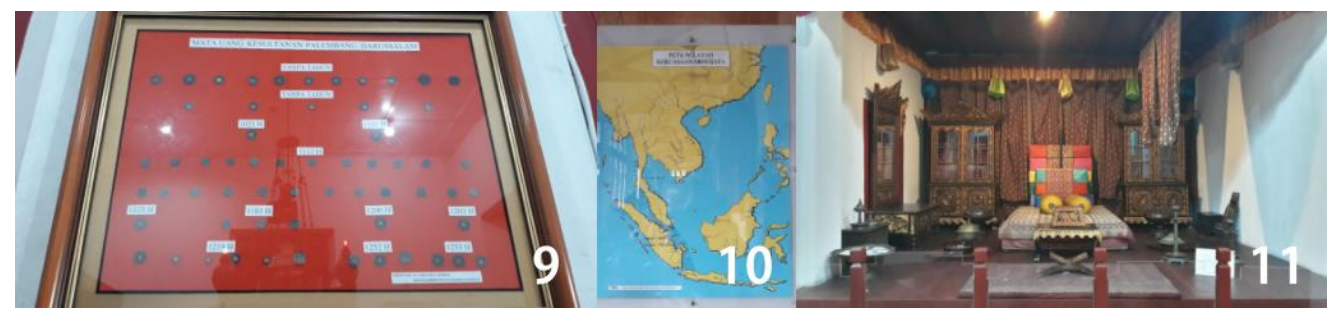

Gambar 4 Beberapa contoh koleksi Museum SMB II: Nomor 9) Koleksi mata uang koin klasik;

10) Peta wilayah kekuasan Sriwijaya; 11) Interior Kamar Tidur klasik adat Palembang. sumber: Haswati, 2020

Sedangkan ilmu periklanan berperan sebagai elemen pendukung dalam perancangan seluk beluk komunikasi yang interaktif, persuasif, hingga strategi pemasaran yang lebih kreatif serta efektif antara museum dan target 
sasarnya. Lebih lanjut, untuk menunjang biaya operasional museum agar dapat beroperasi secara mandiri tanpa terlalu bergantung pada anggaran pemerintah, maka rencana standardisasi pun harus mempertimbangkan berbagai inovasi bisnis dan strategi pemasaran agar museum dapat lebih mandiri secara finansial. Dengan demikian, dengan memanfaatkan Participatory Design yang menggabungkan variabel-variabel tersebut, penelitian ini dimaksudkan sebagai sebuah cetak biru dalam menyusun garis besar tahap apa saja yang sebaiknya dilakukan oleh pengelola museum dalam kurun waktu tertentu.

Meskipun bersifat dinamis, masing-masing dari ketiga poin klasifikasi data pada Bab Metode Penelitian merupakan navigasi yang berfungsi mengarahkan kajian, konsep, serta implementasi Participatory Design agar tetap konsisten pada konteks keilmuan yang telah ditentukan-yakni desain dan periklanan. Bagaimanapun, dibutuhkan berbagai perspektif dari lintas keilmuan seperti sejarah, psikologi, antropologi (sosial budaya), bisnis inovasi, dan sebagainya. Hal ini disebabkan oleh orientasi penelitian ini terhadap aspek manusia, baik sebagai individu maupun sebagai bagian dari suatu komunitas tertentu. Pernyataan yang sama juga dikemukakan IDEO.org (2015) dalam panduan Design Kit: "The Field Guide to Human-Centered Design" sebagai 3 (tiga) tahapan penting proses perancangan solusi, yakni Inspirasi, Penggalian Ide, dan Implementasi.

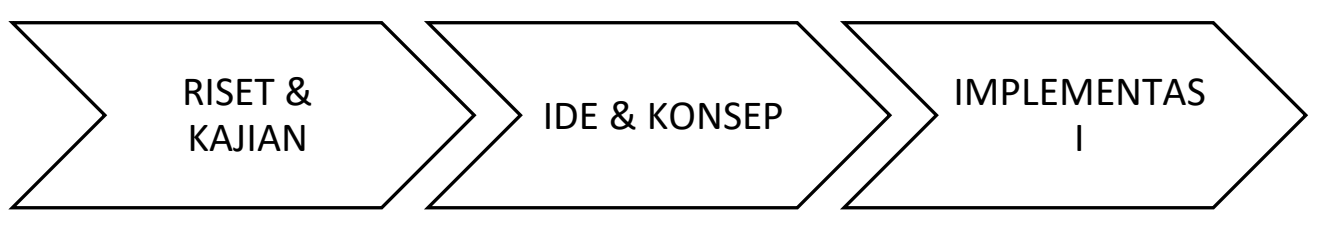

Gambar 4 Proses Design

sumber : Haswati, et Al, 2020 
Dapat dilihat bahwa workflow dalam Participatory Design pada gambar 4 hampir sama dengan proses desain pada umumnya. Hal yang membedakannya hanyalah seberapa aktif keterlibatan pengguna dalam proses desain tersebut. Pengguna merupakan individu-individu yang bersinggungan dengan Museum; yakni Stakeholders atau pengelola Museum, Kurator, bahkan pengunjung, Dalam konteks Participatory Design untuk museum, keterlibatan para pengguna dapat dimanifestasikan oleh kegiatan diskusi terbuka serupa Forum Group Discussion maupun berbagai jenis aktivitas interaktif yang ditawarkan oleh panduan Human-Centered Design oleh IDEO.org dalam paragraf sebelumnya.

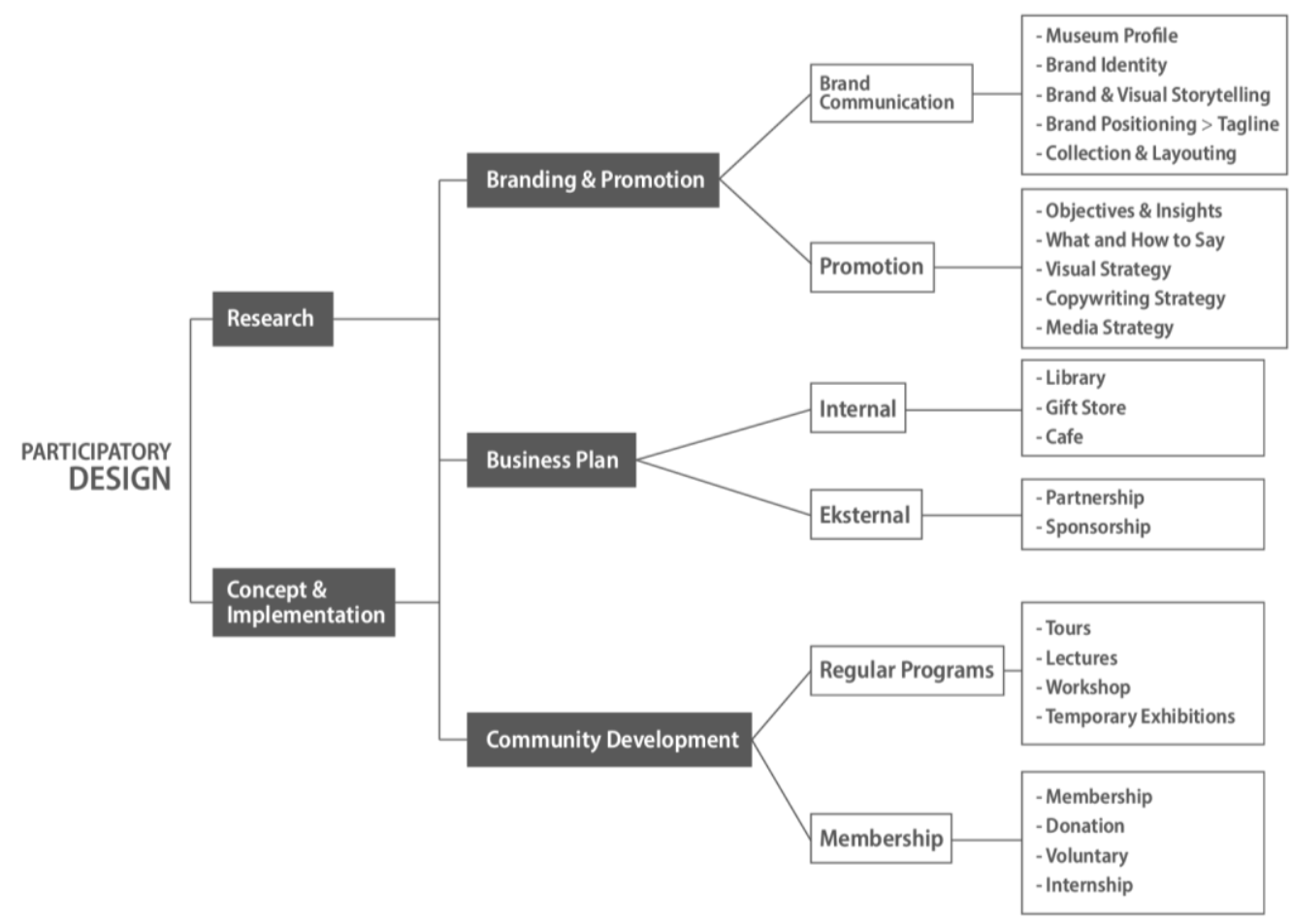

Gambar 5 Skema Penerapan Participatory Design pada Standarisasi Museum Sultan Mahmud Badaruddin II Sumber: Haswati, et Al, 2020 
Penelitian ini mengawali tahap pertama, yaitu riset dan kajian dimana rencana pengembangan Museum SMB II menuju standardisasi banyak disesuaikan berdasarkan realita yang terjadi di lapangan. Melibatkan tim yang terdiri atas beberapa praktisi dan akademisi, dua tahap tersebut sudah mulai dilakukan sejak bulan Maret 2020. Sedangkan roadmap proyek desain meliputi masing-masing konsep dan implementasi yang diajukan kepada pengelola museum berkisar kurang lebih selama 5 (lima) tahun terhitung sejak caturwulan terakhir 2020. Belum diketahui persis berapa lama waktu yang dibutuhkan untuk setiap tahapan yang tertera pada gambar 5. Juga tidak menutup kemungkinan bahwa ketika tahapan riset \& kajian masih berlangsung, maka tahapan selanjutnya mulai dapat dilakukan. Bahkan ketika sebuah tahapan sementara berlangsung, bisa jadi membuka opsi-opsi lain yang bersifat lebih konstruktif.

\section{Branding \& Promotion}

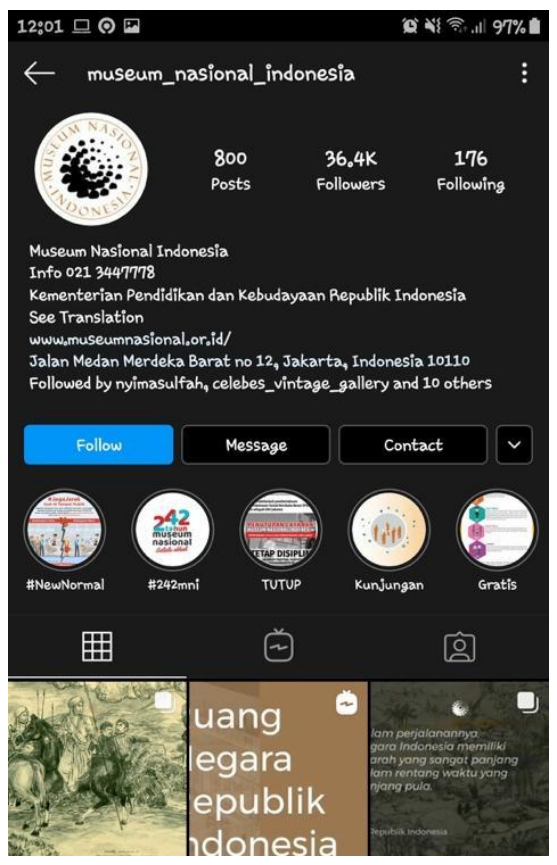

Gambar 6 Tampilan akun resmi Instagram Museum Nasional Sumber: Instagram @museum_nasional_indonesia 
Tidak ubahnya sebuah produk, museum merupakan sebuah entitas yang membutuhkan lebih dari sekedar nama atau label semata. Sesuatu yang kuat serta bermakna sehingga memunculkan kesan serta keterikatan di level emosional dengan target sasarnya. Sayangnya identitas sebuah museum tidak muncul begitu saja, melainkan harus dibuat dengan cermat dan dikomunikasikan secara kreatif, secara konsisten melalui berbagai macam strategi. Di ranah bisnis dan industri sendiri-Identitas tersebut diwakili oleh Brand, sementara proses perancangan Brand ini disebut dengan istilah Branding, yakni mengukuhkan satu citra yang mampu merepresentasikan banyak nilai: Sejarah museum, karakteristiknya, siapa orang-orang di baliknya, itikad, cita-citanya, bahkan siapa yang menjadi alasan museum itu tetap bertahan. Dalimunthe and Nurunnisha (2017) menyebutkan bahwa Branding merupakan sebuah cara yang digunakan untuk menentukan (citra) sebuah tempat sekaligus menarik perhatian khalayak ramai di tengah membanjirnya aliran informasi saat ini.

Tidak berhenti sampai disitu, untuk memastikan bahwa komunikasi Brand dapat diterima dengan baik oleh khalayak luas, dibutuhkan serangkaian aktivitas periklanan, promosi yang berfungsi tidak hanya menginformasikan; namun juga mengajak, mengingatkan, memotivasi, hingga mengukuhkan paradigma tertentu yang berujung pada terbentuknya perilaku target sasar sesuai dengan tujuan pengiklan. Apalagi jika didukung dengan pemilihan media yang tepat, maka dapat mempengaruhi visibilitas organisasi tersebut dengan cara menentukan kemana perhatian publik ingin diarahkan (Zakakis et al., 2015). Jika sesuai dengan apa yang ditawarkan, maka museum akan lebih dikenal masyarakat dan terciptalah sebuah citra yang baik maupun asosiasi-asosiasi yang positif sehingga berdampak pada peningkatan jumlah pengunjung (Nuraeni et al., 2014). 
Tabel 3 Penjabaran Area Brand \& Promotion

\begin{tabular}{|c|c|c|}
\hline & & Output \\
\hline \multirow{12}{*}{$\begin{array}{l}\text { Brand } \\
\text { Communication } \\
\text { (long term) }\end{array}$} & \multirow[t]{4}{*}{ Museum Profile } & Pamphlet, Flyer, Brochure, \\
\hline & & Website, Social Media Contents, \\
\hline & & Mobile Application, \\
\hline & & Merchandises, etc. \\
\hline & \multirow[t]{2}{*}{ Brand Identity } & Guide Book, Logo, Color, Visual \\
\hline & & Attributes, Sign System, etc. \\
\hline & \multirow[t]{2}{*}{ Storytelling } & Brand Story, Narration, Caption, \\
\hline & & Description of Collection, etc. \\
\hline & \multirow[t]{2}{*}{ Brand Positioning } & Slogan, Tagline, Positioning, \\
\hline & & keywords, hashtags, etc. \\
\hline & \multirow[t]{2}{*}{ Collection \& Layout } & Layout plan, display concept \& \\
\hline & & guideline, interior moodboard \\
\hline \multirow{10}{*}{$\begin{array}{l}\text { Promotion } \\
\text { (short term) }\end{array}$} & \multirow[t]{2}{*}{ Objective \& Insights } & Activation, Campaigns, Mobile \\
\hline & & Exhibition, etc. \\
\hline & \multirow[t]{3}{*}{ What \& How To Say } & Market Research, FAB, \\
\hline & & Communication Message, \\
\hline & & Voice of Tone, Big Idea, etc. \\
\hline & Visual Strategy & Visual Approaches \\
\hline & Copywriting Strategy & Linguistic Approaches \\
\hline & \multirow[t]{3}{*}{ Media Strategy } & Conventional, Digital, \\
\hline & & Mixed Media, Ambient Media, \\
\hline & & New Media, etc. \\
\hline
\end{tabular}
sumber : Haswati, et Al, 2020

Kendati demikian, efektivitas Branding maupun promosi museum juga ditentukan oleh banyak faktor. Dikutip dan disederhanakan dari Meenaghan (1995) bahwasanya para pakar merumuskan beberapa diantaranya: 1) Faktor fisik, seperti kualitas produk (contohnya model arsitektur museum atau keunikan koleksi); 2) Faktor non-fisik, seperti kualitas pelayanan; dan 3) Faktor manusia. Dalam hal ini yang bisa dikembangkan oleh desainer adalah faktor fisik seperti media informasi, tata letak, dan penyajian koleksi, sedangkan kualitas pelayanan sangat berkaitan dengan kemampuan internal museum untuk memberikan pelatihan maupun sertifikasi untuk meningkatkan kompetensi para stafnya. 


\section{Business Plan}

Ada begitu banyak alasan rasional mengapa pengelola museum kini harus mempertimbangkan peluang bisnis. Dalam literasi-literasi barat, istilah Museum Marketing sudah tidak asing lagi bagi akademisi maupun praktisi museum. Menurut McLean (2012) museum merupakan institusi sosial yang memiliki tujuan sosial pula, sehingga penerapan marketing di museum pun harus merefleksikan target-target sosial yang tersebut. Apalagi dengan tersedianya fasilitas-fasilitas pendukung tentu saja bisa menjadi penarik minat pengunjung agar lebih betah di museum. Sehingga tidak heran jika museummuseum pun semakin bersaing dalam memberikan penawaran dan kualitas pelayanan yang senilai dengan waktu serta uang yang akan dihabiskan oleh pengunjung (Hume, 2011).

Rentschler and Hede (2007) mengulas dalam bukunya bahwa di jaman yang serba modern ini, kafe dan toko souvenir adalah dua fasilitas standar yang sudah dimiliki museum pada umumnya. Toko souvenir bisa menyediakan cenderamata seperti kartu pos, buku-buku yang berkaitan dengan tema koleksi, dan variasi merchandise yang mewakili signature dari museum tersebut sehingga bisa dibeli pengunjung untuk memantik memori selama melakukan kunjungan.

Sementara itu, kafe bisa menyediakan ruang santai bagi pengunjung sehingga mereka tidak perlu keluar dari area museum jika ingin bersantap, sekedar berbincang-bincang, atau sambil berdiskusi. Bahkan menurut hasil riset Jafari et al. (2013) bahwa sebagian besar informan mereka setuju bahwa kafe museum merupakan sarana sosialisasi yang menyenangkan. Orangorang asing dapat saling menyapa dan mengobrol tentang museum atau pameran yang bersangkutan. Keberadaan dua tempat tersebut sedikit banyak juga akan berkontribusi terhadap pembentukan identitas museum di benak target sasar. Sekalipun diramu melalui media yang sederhana, sepanjang 
fasilitas museum mampu dirancang agar ramah terhadap pengunjung maka dapat melahirkan kesan-kesan yang positif. Apalagi jika diperkuat dengan implementasi komunikasi Branding (salah satunya dari strategi visual yang tepat, misalnya dari sisi grafis, pemilihan warna, dll) hingga didukung oleh aktivitas promosi yang menarik dan kreatif.

Tabel 4 Penjabaran Area Business Plan

\begin{tabular}{lll}
\hline Internal & \multicolumn{1}{c}{ Output } \\
\cline { 2 - 2 } & Library & $\begin{array}{l}\text { Business Plan: } \\
\text { Gift Store }\end{array}$ \\
\cline { 2 - 3 } & Concept to Implementation \\
\hline External & $\begin{array}{l}\text { Sponsorship \& } \\
\text { Partnership }\end{array}$ & Project Scheme \\
& & \\
\hline
\end{tabular}

sumber : Haswati, et Al, 2020

Bahkan jika memungkinkan, museum bisa menyewakan beberapa ruang untuk iklan atau media yang memuat informasi lain dengan memanfaatkan model kerjasama bisnis baik sponsorship maupun partnership. Contohnya Museum Fujiko Fujio (Doraemon) di Jepang yang disponsori (atau sementara berstatus sebagai mitra resmi) Odakyu Railway, Panasonic, dan Line Game. Model ini bisa coba diterapkan di Palembang, didukung oleh fakta bahwa salah satu Stasiun LRT (Light Rail Transit) yang kini sibuk beroperasi hilir mudik dari Bandara Sultan Mahmud Badaruddin II berada persis di sisi kiri lokasi museum yang bernama sama itu. Dengan merangkul pihak lain untuk ikut meramaikan museum, secara tidak langsung museum juga mendukung terbentuknya ekosistem pariwisata yang berkelanjutan bagi banyak orang.

\section{Community Development}

Seperti yang telah dibahas, faktor manusia merupakan salah satu elemen yang paling signifikan dalam proses perancangan Branding maupun promosi, dalam hal ini bagi sebuah museum. Sebagai Public Service, pihak 
museum harus memahami pola-pola atau kecenderungan tertentu dari kunjungan museum secara keseluruhan (Hooper-Greenhill, 2013). Dalam dunia marketing dan advertising, hal tersebut diistilahkan sebagai perilaku konsumen: siapa mereka, apa yang mereka inginkan, bagaimana cara berpikirnya, dan lain-lain. Maka dari itu dilakukanlah prosedur penelitian tertentu untuk menggali lebih dalam sebenarnya apa yang memotivasi masyarakat untuk lebih lebih sering datang ke museum.

Tabel 5 Penjabaran Area Community Development

\begin{tabular}{|c|c|c|}
\hline & & Output \\
\hline \multirow[t]{4}{*}{ Regular Program } & Tours & \multirow{8}{*}{$\begin{array}{l}\text { Program Scheme: } \\
\text { Concept to Implementation }\end{array}$} \\
\hline & Open Lectures & \\
\hline & Workshop & \\
\hline & Temporary Exhibition & \\
\hline \multirow[t]{4}{*}{ Membership } & Membership & \\
\hline & Voluntary Program & \\
\hline & Donation & \\
\hline & Internship & \\
\hline
\end{tabular}

Namun jika menyinggung kembali pembahasan mengenai museum yang berkelanjutan, faktor manusia tidak cukup merujuk kepada pengunjung semata. Melainkan kemampuan museum mengajak komunitas setempat agar ikut berpartisipasi dalam pengembangan program yang akan mereka dijalankan. Jika dipaparkan satu per satu, maka banyak sekali contoh keterlibatan komunitas yang bisa dijadikan rujukan oleh Museum SMB II dan terbukti efektif dalam mendorong kepuasan pengunjung serta melahirkan keterikatan emosional terhadap museum. Misalnya program dari biro perjalanan yang bekerja sama dengan museum dalam bentuk penawaran paket perjalanan wisata kawasan sejarah seraya melibatkan pelatihan membuat kain jumputan atau menulis aksara kuno Sriwijaya, apalagi jika disertai cenderamata yang menarik. Atau sebuah pameran khusus yang berfungsi menarik minat target sasar, misalnya mengadakan pameran tematik 
tentang fesyen di era kesultanan Palembang dengan melibatkan komunitas pecinta kain Songket, atau pertunjukan musikalisasi yang melibatkan seniman lokal hingga pengrajin alat musik tradisional.

Di samping itu, sudah banyak sekali museum yang menawarkan program keanggotaan atau membership kepada komunitas maupun para individu yang tertarik untuk mendapatkan privilege tertentu mengenai segala sesuatu mengenai museum yang bersangkutan (Wallace, 2016). Mereka memperoleh buletin bulanan, tiket masuk gratis, diskon berbelanja di kafe atau toko souvenir milik museum, dan lain-lain. Lebih jauh lagi, program keanggotaan ini biasanya dipasangkan dengan program donasi perorangan sehingga manfaat program bersifat mutualisme. Begitu pula dengan sistem sukarela bagi masyarakat yang ingin terlibat dalam pengembangan museum namun tidak secara material. Biasanya target yang disasar sebagai tenaga sukarelawan museum adalah para pelajar atau mahasiswa yang juga berhak mendapatkan timbal balik berupa benefit tertentu atas jasanya.

Penyelenggara dari program pengembangan komunitas tidak terbatas pada pengelola museum semata, namun sasarannya adalah bagaimana melibatkan sebanyak mungkin lapisan masyarakat (sesuai dengan karakteristik dan kompetensinya) sekaligus memberdayakan mereka (Muntu et al., 2018) sehingga secara perlahan dapat membentuk satu kawasan wisata sejarah yang bernilai ekonomis sehingga dapat menggerakkan sektor-sektor lainnya.

\section{KESIMPULAN}

Mengelola museum adalah pekerjaan rumah yang besar, tidak hanya bagi pekerja museum itu sendiri, tapi juga bagi masyarakat yang hidup dan berkegiatan di sekitarnya. Bagaimanapun, untuk mencapai kondisi yang ideal di mana museum bisa dimanfaatkan oleh masyarakat sebagai sekolah kedua, 
sumber penghidupan, sekaligus tujuan wisata utama yang berkesan, dibutuhkan pendampingan secara khusus oleh tim desain melalui pendekatan Participatory Design. Skema aktifitas-aktifitas yang berhubungan dengan kajian, konsep, serta implementasi Participatory Design (yang meliputi Branding \& Promotion, Business Plan, dan Community Development) dapat dijadikan rujukan utama oleh pengelola Museum SMB II serta dilaksanakan baik secara paralel maupun secara bertahap sekaligus membuktikan teori Sanders mengenai implementasi Participatory Design. Namun mengingat penelitian ini merupakan satu tahap utama dalam preliminary design yang berfungsi untuk mendukung rangkaian perancangan desain sesudahnya: yakni collecting data, maka terdapat banyak informasi pendukung dan detail yang masih belum dimuat oleh penulis melainkan akan dibahas pada tulisantulisan selanjutnya. Maka dari itu, dapat disimpulkan bahwa penelitian mengenai implementasi Participatory Design pada Museum SMB II ini sangat menarik untuk dikaji.

\section{PERNYATAAN PENGHARGAAN}

Tim penulis menyampaikan terima kasih atas dukungan berbagai pihak yang membantu proses penulisan artikel ini dari awal pengumpulan data, penyelenggaraan Forum Group Discussion di Palembang, hingga terancangnya skema implementasi Participatory Design; terutama Ibu Nyimas Ulfah Aryeni, S.S., M.Si selaku Kepala Seksi Museum Sultan Mahmud Badaruddin II beserta jajaran staf Museum SMB II; Tim Kreatif Projek Standardisasi Museum SMB II; Klub Diskusi BGSS dan Bapak Ilhamsyah atas segala perputaran wawasan, humor-humor satir, serta masukan ke penulisan akademik yang benar. Dan terakhir, kepada pihak-pihak yang namanya tidak bisa kami sebutkan satu per satu. 


\section{DAFTAR PUSTAKA}

Anonim N.D. Logo Museum Nasional. In: NASIONAL, L. M. (ed.). Jakarta: Kementerian Pendidikan dan Kebudayaan, Direktorat Jenderal Kebudayaan,.

Arthur, P. \& Passini, R. 1992. Wayfinding: People, Signs, and Architecture, the University of Michigan, McGraw-Hill Book Company.

Boylan, P. 2004. Running a Museum. Paris: UNESCO-ICOM.

Dalimunthe, G. P. \& Nurunnisha, G. A. 2017. Komunitas Aleut and History-Based Tourism in City Branding: The Case of Bandung, West Java, Indonesia. Review of Integrative Business and Economics Research, 6, page 264.

Direktorat Pelestarian Cagar Budaya dan Permuseuman, Direktorat Jenderal Kebudayaan \& Kementerian Pendidikan dan Kebudayaan 2017. Pedoman Standardisasi Museum Bagi Pengelola. Jakarta.

Hadi, D. W., Permanawhiyat, W., Sambodo, N., Anindyatri, A. O. \& Mas`ad 2019. Statistik Kebudayaan 2019. Jakarta: Kementerian Pendidikan dan Kebudayaan.

Hooper-Greenhill, E. 2013. Museums and Their Visitors, New York, Taylor \& Francis.

Hume, M. 2011. How Do We Keep Them Coming?: Examining Museum Experiences Using a Services Marketing Paradigm. Journal of Nonprofit \& Public Sector Marketing, 23, 71-94.

IDEO.org 2015. The Field Guide to Human-Centered Design. In: IDEO.ORG (ed.) 1st Edition ed. Canada: IDEO.org.

Jafari, A., Taheri, B. \& Vom Lehn, D. 2013. Cultural Consumption, Interactive Sociality, and the Museum. Journal of Marketing Management, 29, 17291752.

Kemdikbud 2015. Peraturan Pemerintah Republik Indonesia Nomor 66 Tahun 2015 Tentang Museum. In: KEBUDAYAAN, K. P. D. (ed.). kebudayaan.kemdikbud.go.id.

McLean, F. 2012. Marketing the Museum, London, Routledge.

Meenaghan, T. 1995. The Role of Advertising in Brand Image Development. Journal of product \& brand management, 4 pages 23-34.

Menbudpar 2009. Peraturan Menteri Kebudayaan Dan Pariwisata: Pedoman Permuseuman. In: MENBUDPAR (ed.). Jakarta: Kementerian Pariwisata dan Ekonomi Kreatif.

Muntu, A. W., Wiranatha, A. S. \& Arida, I. N. S. 2018. Analisis Partisipasi Komunitas Lokal Dalam Pengembangan Daya Tarik Wisata Kota Tua Jakarta. Jurnal Master Pariwisata (JUMPA), 4, pages 173-188.

Nuraeni, B. S., Ferdinand, A. T. \& Sufian, S. 2014. Analisis Faktor-Faktor Yang Mempengaruhi Minat Kunjung Ulang Wisatawan Museum Ranggawarsita Semarang. Diponegoro University. 
Rentschler, R. \& Hede, A. M. 2007. Museum Marketing: Competing in the Global Marketplace, Oxford, Butterworth-Heinemann.

Suwena, I. K., Widyatmaja, I. G. N. \& Atmaja, M. J. 2010. Pengetahuan Dasar IImu Pariwisata, Udayana University Press.

Trulove, J. G., Sprague, C. \& Colony, S. 2000. This Way: Signage Design for Public Spaces, Massachusetts, Rockport.

Wallace, M. 2016. Museum Branding: How to Create and Maintain Image, Loyalty, and Support, Oxford, Rowman \& Littlefield Publishers.

Yeo, W. 2013. Palembang in the 1950s: The Making and Unmaking of a Region. Doctor Thesis, University of Washington.

Zakakis, N., Bantimaroudis, P. \& Zyglidopoulos, S. 2015. Museum Promotion and Cultural Salience: The Agenda of the Athenian Acropolis Museum. Museum Management and Curatorship, 30, 342-358. 